\title{
$\alpha$-Lipoic acid regulates lipid metabolism through induction of sirtuin 1 (SIRT1) and activation of AMP-activated protein kinase
}

\author{
W.-L. Chen • C.-H. Kang $•$ S.-G. Wang $・$ H.-M. Lee
}

Received: 1 January 2011 / Accepted: 13 February 2012 / Published online: 30 March 2012

(C) Springer-Verlag 2012

\begin{abstract}
Aims/hypothesis Sirtuin 1 (SIRT1) is a longevity-associated protein, which regulates energy metabolism and lifespan in response to nutrient deprivation. It has been proposed to be a therapeutic target for obesity and metabolic syndrome. We investigated whether $\alpha$-lipoic acid (ALA) exerts a lipidlowering effect through regulation of SIRT1 activation and production in $\mathrm{C}_{2} \mathrm{C}_{12}$ myotubes.

Methods ALA-stimulated AMP-activated protein kinase (AMPK), acetyl-CoA carboxylase (ACC), adipose triacylglycerol lipase (ATGL) and fatty acid synthase (FAS) production, as well as intracellular triacylglycerol accumulation and fatty acid $\beta$-oxidation were analysed in the absence or presence of a SIRT1 inhibitor (nicotinamide), SIRT1 small interfering (si) RNA and an AMPK inhibitor (compound C) in $\mathrm{C}_{2} \mathrm{C}_{12}$ myotubes. Mice with streptozotocin/nicotinamideinduced diabetes and $d b / d b$ mice fed on a high-fat diet were
\end{abstract}

Electronic supplementary material The online version of this article (doi:10.1007/s00125-012-2530-4) contains peer-reviewed but unedited supplementary material, which is available to authorised users.

W.-L. Chen · C.-H. Kang • H.-M. Lee $(\triangle)$

Graduate Institute of Medical Sciences, College of Medicine,

Taipei Medical University,

$250 \mathrm{Wu}-\mathrm{Hsing}$ Street,

Taipei 110, Taiwan

e-mail: leehorng@tmu.edu.tw

W.-L. Chen · C.-H. Kang • H.-M. Lee

School of Medical Laboratory Sciences and Biotechnology,

College of Medicine, Taipei Medical University,

Taipei, Taiwan

S.-G. Wang • H.-M. Lee

Institute of Pharmaceutical Sciences and Technology,

Central Taiwan University of Science and Technology,

Taichung, Taiwan used to study the ALA-mediated lipid-lowering effects in vivo.

Results ALA increased the $\mathrm{NAD}^{+} / \mathrm{NADH}$ ratio to enhance SIRT1 activity and production in $\mathrm{C}_{2} \mathrm{C}_{12}$ myotubes. ALA subsequently increased AMPK and ACC phosphorylation, leading to increased palmitate $\beta$-oxidation and decreased intracellular triacylglycerol accumulation in $\mathrm{C}_{2} \mathrm{C}_{12}$ myotubes. In cells treated with nicotinamide or transfected with SIRT1 siRNA, ALA-mediated AMPK/ACC phosphorylation, intracellular triacylglycerol accumulation and palmitate $\beta$-oxidation were reduced, suggesting that SIRT1 is an upstream regulator of AMPK. ALA increased ATGL and suppressed FAS protein production in $\mathrm{C}_{2} \mathrm{C}_{12}$ myotubes. Oral administration of ALA in diabetic mice fed on a high-fat diet and $d b / d b$ mice dramatically reduced the body weight and visceral fat content.

Conclusions/interpretation ALA activates both SIRT1 and AMPK, which leads to lipid-lowering effects in vitro and in vivo. These findings suggest that ALA may have beneficial effects in the treatment of dyslipidaemia and obesity.

Keywords AMPK $\cdot$ ATGL $\cdot \alpha$-Lipoic acid $\cdot$ SIRT1

$\begin{array}{ll}\text { Abbreviations } \\ \text { ACC } & \text { Acetyl-CoA carboxylase } \\ \text { AICAR } & \text { 5-Aminoimidazole-4-carboxamide riboside } \\ \text { ALA } & \alpha \text {-Lipoic acid } \\ \text { AMPK } & \text { AMP-activated protein kinase } \\ \text { ATGL } & \text { Adipose triacylglycerol lipase } \\ \text { FAS } & \text { Fatty acid synthase } \\ \text { FOXO } & \text { Forkhead box O } \\ \text { GAPDH } & \text { Glyceraldehyde-3-phosphate dehydrogenase } \\ \text { HRP } & \text { Horseradish peroxidase } \\ \text { LKB-1 } & \text { Liver kinase B1 }\end{array}$


NA Nicotinamide

NAMPT Nicotinamide phosphoribosyltransferase

siRNA Small interfering RNA

SIRT-1 Sirtuin 1

STZ Streptozotocin

\section{Introduction}

$\alpha$-Lipoic acid (ALA) is an endogenous cofactor in many multi-enzyme complexes that catalyse the oxidative decarboxylation of $\alpha$-keto acids such as pyruvate and $\alpha$-ketoglutarate. ALA is a powerful antioxidant derived from plants and animal tissues [1]. It has been shown to reduce body weight by suppressing hypothalamic AMP-activated protein kinase (AMPK) [2]. It increases insulin sensitivity and skeletal muscle fatty acid oxidation by activating AMPK in diabetes-prone Otsuka Long Tokushima fatty rats [3, 4]. It also increases glucose uptake in 3T3-L1 adipocytes [5], skeletal muscle cells [6] and skeletal muscles of $o b / o b$ mice [7]. Treatment with ALA ameliorates severe hypertriacylglycerolaemia by inhibiting triacylglycerol synthesis and VLDLtriacylglycerol secretion in Zucker diabetic fatty rats [8]. Thus, ALA has potent beneficial effects on obesity, type 2 diabetes mellitus and dyslipidaemia.

Sirtuin 1 (SIRT1) is a class III NAD ${ }^{+}$-dependent histone/ protein deacetylase that regulates lipid metabolism and lifespan by deacetylating lysine residues on various transcription factors [9]. It deacetylates the transcription factor of forkhead box O protein (FOXO) [10], p53 [11] and peroxisome proliferator-activated receptor- $\gamma$ coactivator $1 \alpha$ (PGC-1 $\alpha$ ) to control metabolic functions [12] and biological processes [13] similar to those observed with energy restriction. Decreased SIRT1 production may have a critical role in the pathogenesis of type 2 diabetes [14] and insulin resistance, which is associated with SIRT1 downregulation of type 2 diabetes [15]. SIRT1 is regulated by $\mathrm{NAD}^{+}$, the concentration of nicotinamide (NA), and the activity of nicotinamide phosphoribosyltransferase (NAMPT). When ALA is taken up by cells, it is converted into dihydrolipoate by mitochondrial lipoamide dehydrogenase or the thioredoxin/thioredoxin reductase system, which couples the conversion of NADH into $\mathrm{NAD}^{+}$and increases the $\mathrm{NAD}^{+}$/ NADH ratio. NA, an inhibitor of SIRT1, can be converted into $\mathrm{NAD}^{+}$by phosphoribosylation catalysed by NAMPT, and NAMPT is activated by nutrient deprivation, exercise and AMPK activation [16]. Therefore, nutrient deprivation may increase SIRT1 activity by increasing the $\mathrm{NAD}^{+} /$ NADH ratio and by decreasing the abundance of NA. However, whether ALA regulates SIRT1 activity or production has not been determined.

AMPK, a fuel-sensing enzyme, exerts effects similar to SIRT1 on cellular energy metabolism and mitochondrial biogenesis $[17,18]$. Once activated, AMPK phosphorylates acetyl-CoA carboxylase (ACC), thereby blocking its activity. This in turn decreases malonyl-CoA concentration, leading to enhanced mitochondrial fatty acid $\beta$-oxidation. The AMPK signalling pathway is thought to be a natural response to reduce dyslipidaemia and to ameliorate insulin resistance [19]. Therefore, activation of SIRT1/AMPK signalling may offer significant pharmacological benefits in treating dyslipidaemia, obesity and metabolic syndrome. Because of the aforementioned metabolic actions of SIRT and AMPK, we investigated whether ALA regulated lipid metabolism through the SIRT1 and AMPK signalling pathway. We demonstrated that ALA activated and induced SIRT1 production and function as an upstream regulator of AMPK. ALA also enhanced ATGL and suppressed fatty acid synthase (FAS) production, which in turn reduced lipid accumulation in $\mathrm{C}_{2} \mathrm{C}_{12}$ cells exposed to high glucose. These data suggest that ALA may exert beneficial effects in treating dyslipidaemia and obesity of the metabolic syndrome.

\section{Methods}

Materials DMEM, FCS, glutamine, gentamicin, penicillin and streptomycin were purchased from Life Technologies (Gaithersburg, MD, USA). Rabbit polyclonal antibodies to FAS, acetyl-lysine and glyceraldehyde-3-phosphate dehydrogenase (GAPDH) were from Gentex (Irvine, CA, USA). Antibodies to phospho-AMPK, AMPK, ATGL, phospho-ACC and ACC were obtained from Cell Signaling Technology (Danvers, MA, USA). Rabbit polyclonal antiSIRT1, mouse polyclonal anti- liver kinase B1 (LKB-1) and horseradish peroxidase (HRP)-conjugated anti-mouse and anti-rabbit secondary antibodies were obtained from Santa Cruz Biotechnology (Santa Cruz, CA, USA). 5-Aminoimidazole-4-carboxamide riboside (AICAR), compound $\mathrm{C}$ and NA were purchased from CalbiochemNovabiochem (San Diego, CA, USA). HRP-conjugated antirabbit IgG was purchased from Bio-Rad (Hercules, CA, USA). SIRT1 assay kits were from BIOMOL (Plymouth Meeting, PA, USA).

Culture of $\mathrm{C}_{2} C_{12}$ myotubes and preparation of cell lysates $\mathrm{C}_{2} \mathrm{C}_{12}$ skeletal muscle cells were cultured in DMEM supplemented with $10 \%$ heat-inactivated FCS and penicillin $(100 \mathrm{U} / \mathrm{ml}) /$ streptomycin $(100 \mathrm{mg} / \mathrm{ml})$. After reaching confluence, $\mathrm{C}_{2} \mathrm{C}_{12}$ cells were differentiated to myotubes by the addition of $2 \%$ horse serum for $96 \mathrm{~h}$ as described by Lagouge et al [20], and these myotubes were treated with various concentrations of the indicated agents and incubated for the indicated periods in a $5 \% \mathrm{CO}_{2}$ humidified incubator at $37^{\circ} \mathrm{C}$. Cells were scraped off using a rubber policeman to obtain cell lysates for the experiments. 
Immunoprecipitation and western blotting Proteins from cell lysates were separated by SDS-PAGE and transferred to poly(vinylidene difluoride) membranes for immunoblotting. Membranes were blocked with blocking solution containing 3\% BSA and $0.1 \%$ Tween 20 in PBS for $1 \mathrm{~h}$ at room temperature followed by incubation with the primary and secondary antibodies. For immunoprecipitation, the agarose beads were conjugated with antibody to LKB-1. Protein $(500 \mu \mathrm{g})$ from cultured cells was incubated with crosslinked LKB-1 beads overnight, and the immunoprecipitates were boiled with sample loading buffer containing $0.5 \mathrm{~mol} /$ $1 \mathrm{TRIS} / \mathrm{HCl}$ (pH 6.8), 4.4\% (wt/vol.) SDS, 20\% (vol./vol.) glycerol, 2\% (vol./vol.) 2-mercaptoethanol and bromophenol blue in distilled/deionised water for $5 \mathrm{~min}$ before SDSPAGE. Immunodetection was performed using a LumiGLO chemiluminescence kit (Amersham International, Amersham, UK). Levels of phosphorylation and abundance were quantified by scanning densitometry using a model GS-700 imaging densitometer (Bio-Rad), normalised to levels of total protein.

Transfection of SIRT1-specific small interfering (si) $R N A \mathrm{C}_{2} \mathrm{C}_{12}$ cells were seeded at $5 \times 10^{5}$ cells per $6 \mathrm{~cm}$ plate and allowed to adhere overnight. SIRT1-specific siRNA was transfected into cells using lipofectamine (Invitrogen, Grand Island, NY, USA) after $48 \mathrm{~h}$ of differentiation. After $48 \mathrm{~h}$, transfected cells were treated with ALA $(300 \mu \mathrm{mol} / \mathrm{l})$ for $24 \mathrm{~h}$. Cell lysates were collected in parallel for the western blot analysis.

Measurement of SIRT1 activity SIRT1 activity was assayed by a Fluor-de-Lys fluorescence assay kit (BIOMOL) according to the manufacturer's instructions. Briefly, the assay was performed by incubating recombinant human SIRT1 protein and substrates, including a fluorogenic acetylated Lys 382 p53 peptide $(50 \mu \mathrm{mol} / \mathrm{l})$ and $\mathrm{NAD}^{+}(100 \mu \mathrm{mol} / \mathrm{l})$ at $37{ }^{\circ} \mathrm{C}$ for $30 \mathrm{~min}$ according to the manufacturer's instructions. The fluorescence intensity was measured using a Fluoroskan Ascent microplate fluorimeter (Thermo Electron, Milford, MA, USA). Negative controls included 'no enzyme' and 'time zero' controls, in which Developer II solution plus $2 \mathrm{mmol} / \mathrm{l} \mathrm{NA}$ was added before mixing of the substrates with or without the SIRT1 enzyme. SIRT1 activity was calculated with the corrected arbitrary fluorescence units of the tested compounds to the 'no enzyme' control and expressed as fluorescent units relative to the control. To rule out ALA possession of autofluorescence or interference of NA itself with the fluorescent signal, the Developer II solution was incubated with the Fluor-de-Lys deacetylated standard or the tested compounds in the absence of SIRT1 enzyme or substrates. The deacetylated standard dose-dependently increased the fluorescent rate, whereas the tested compounds did not alter the fluorescent intensity, indicating that the change in $\mathrm{p} 53$ deacetylation caused by these compounds depends on the specific SIRT1 activity.

Palmitate $\beta$-oxidation After differentiation, cells were resuspended in medium supplemented with $\left[9,10-{ }^{3} \mathrm{H}\right]$ palmitate in a mixture of the palmitate and $10 \%$ BSA at a $1: 2$ volume ratio. In total, $3.3 \mu \mathrm{l}\left[9,10-{ }^{3} \mathrm{H}\right]$ palmitate and $6.7 \mu \mathrm{l}$ BSA were used per ml of cell culture medium. Each sample used $0.5 \times 10^{6}$ cells in $1 \mathrm{ml}$ medium supplemented with the $\left[9,10-{ }^{3} \mathrm{H}\right]$ palmitate/BSA mixture and cultured for $24 \mathrm{~h}$ in 24-well plates. After $24 \mathrm{~h}$, the supernatant fraction was applied to an ion-exchange column (Dowex 1X8-200; Sigma, St Louis, MO, USA), and ${ }^{3} \mathrm{H}$-labelled water was recovered by elution with $2.5 \mathrm{ml}$ water. A $0.75 \mathrm{ml}$ aliquot was then used for scintillation counting.

Measurement of intracellular triacylglycerol content Intracellular triacylglycerol was assayed using a colorimetric assay (GPO-Trinder Reagent A; Sigma) [21]. Briefly, $30 \mu \mathrm{l}$ triacylglycerol standard or supernatant fraction was added to a 96-well flat-bottom polystyrene plate, and $300 \mu \mathrm{l}$ triacylglycerol reagent was then added to the microplate. The plate was incubated for $5 \mathrm{~min}$, and the absorbance was determined at $520 \mathrm{~nm}$ with a Gen5 data collector (BioTek Instruments, Highland Park, Winooski, VT, USA). Intracellular triacylglycerol levels were normalised to total protein and expressed as $\mu \mathrm{g}$ lipid/mg protein.

$N A D^{+} / \mathrm{NADH}$ ratio measurement The $\mathrm{NAD}^{+} / \mathrm{NADH}$ ratio was measured from whole-cell extracts of $\mathrm{C}_{2} \mathrm{C}_{12}$ myotubes or liver using the Biovision $\mathrm{NAD}^{+} / \mathrm{NADH}$ quantification kit (Biovision, San Francisco, CA, USA). To detect total $\mathrm{NAD}^{+}\left(\mathrm{NADt}\left[\mathrm{NAD}^{+}+\mathrm{NADH}\right]\right), 50 \mu 1$ extracted sample (cell or tissue) was transferred to labelled 96-well plates. Into each well of the NADH standard, $100 \mu$ l of the $\mathrm{NAD}^{+}$Cycling Mix was added at room temperature for 5 min to convert $\mathrm{NAD}^{+}$into NADH. Then $10 \mu \mathrm{NADH}$ developer was added to each well for 1-4 $\mathrm{h}$. The absorbance was determined at $450 \mathrm{~nm}$ with a Biotex Microplate Spectrophotometer. To detect NADH, $\mathrm{NAD}^{+}$needs to be decomposed before the reaction by heating at $60{ }^{\circ} \mathrm{C}$ for $30 \mathrm{~min}$. The sample readings were applied to the NADH standard curve, and the amounts of NADt and $\mathrm{NADH}$ were determined using the equation. At the same time, the $\mathrm{NAD}^{+} / \mathrm{NADH}$ ratio was calculated as: $(\mathrm{NADt}-\mathrm{NADH} / \mathrm{NADH}$. These readings were normalised to the cell number (cell sample) and protein concentration (tissue sample).

Animals The $d b / d b$ mice on a C57BL/6 background (male, 14 weeks old, $50 \mathrm{~g}$ ) were gifts from the Development Center for Biotechnology of Taiwan. The animals were given free access to water and were fed on a standard diet. ALA 
(200 $\mathrm{mg} / \mathrm{kg}$ ) or vehicle was administered orally in the afternoon (14:00-14:30 hours). The serum biochemical profiles, including triacylglycerol, cholesterol, insulin, HDLcholesterol, LDL-cholesterol, aspartate aminotransferase and alanine aminotransferase, were determined with a BiochemImmuno autoanalyser (Brea, CA, USA). Whole blood levels of biochemical variables, including $\mathrm{HbA}_{1 \mathrm{c}}$ and glucose, were also measured with a Biochem-Immuno autoanalyser. The quality controls, calibrations and determining procedures were carried out according to the suppliers' instructions. The glucose tolerance test and histopathological examinations were performed on day 90 .

Streptozotocin/NA-induced diabetes mouse model Male C57BL/6J (6 weeks old) mice were obtained from the Taiwan National Laboratory Animal Center. Streptozotocin (STZ, $100 \mathrm{mg} / \mathrm{kg}$ ) was administered to C57BL/6J mice with NA $(240 \mathrm{mg} / \mathrm{kg})$, twice with an interval of 2 days, and then these mice were fed on a high-fat diet for 4 weeks to induce type 2 diabetes [22]. Mice were randomly separated into three groups for treatment with 0,50 or $200 \mathrm{mg} / \mathrm{kg}$ by oral administration. Plasma glucose concentration and body weight were measured on days $0,7,14$ and 28. Biochemical measurements, glucose tolerance and pathological examinations were performed on day 30 .

Histochemical analysis Liver and muscle were fixed and embedded in tissue-freezing medium (Leica Microsystems,
Wetzlar, Germany) and stored at $-80{ }^{\circ} \mathrm{C}$. The frozen tissue was cut into $7 \mu \mathrm{m}$-thick sections and placed on glass slides. The tissue sections were stained with haematoxylin and eosin, Oil Red or Sudan III. Oil Red staining and Sudan III staining were counterstained with haematoxylin to visualise lipid droplets.

Statistical analysis All data are expressed as the mean \pm SEM, and statistical significance $(p<0.05)$ between experimental groups was determined by a single-factor ANOVA for multiple groups or unpaired $t$ test for two groups.

\section{Results}

ALA increases SIRT1 activity and production by modulating the $N A D^{+} / N A D H$ ratio Recent studies have suggested that SIRT1, a mammalian orthologue of Sirt2, is closely associated with lipid metabolism and obesity [15, 23, 24]. Resveratrol, a well-known antioxidant, has been shown to stimulate SIRT1 activity [25]. ALA is also a naturally occurring antioxidant with potent reactive oxygen species-scavenging activity. To test whether ALA increases SIRT1 deacetylase activity, we first determined ALA-stimulated deacetylation of a fluorogenic acetylated Lys382 p53 peptide, and the result showed that incubation with ALA (30 $\mu \mathrm{mol} / \mathrm{l})$ significantly increased SIRT1 activity (Fig. 1a). Since SIRT1 is an NAD ${ }^{+}$-dependent enzyme that acts as a metabolic sensor of $\mathrm{NAD}^{+}$, we next
Fig. 1 ALA increases SIRT1 activity and production by modulating the $\mathrm{NAD}^{+} / \mathrm{NADH}$ ratio. a A Fluor-de-Lys fluorescence assay was performed using a synthetic acetylated Lys382 p53 peptide and NAD ${ }^{+}$ as the substrate. SIRT1 activity is expressed as arbitrary fluorescence units relative to the control. Data are expressed as the mean $\pm \operatorname{SEM}(n=3)$. $* p<0.05$ compared with control. Intracellular levels of $\mathrm{NAD}^{+}(\mathbf{b})$ and NADH (c), and the $\mathrm{NAD}^{+} / \mathrm{NADH}$ ratio (d) in $\mathrm{C}_{2} \mathrm{C}_{12}$ myotubes treated with $\operatorname{ALA}(300$ and $1,000 \mu \mathrm{mol} / \mathrm{l})$ for $24 \mathrm{~h}$. e Cells were incubated with $300 \mu \mathrm{mol} / 1$ ALA for the indicated time periods $(1,2,6$, 12 , and $24 \mathrm{~h}$ ). The cell lysate was immunodetected with a SIRT1-specific antibody
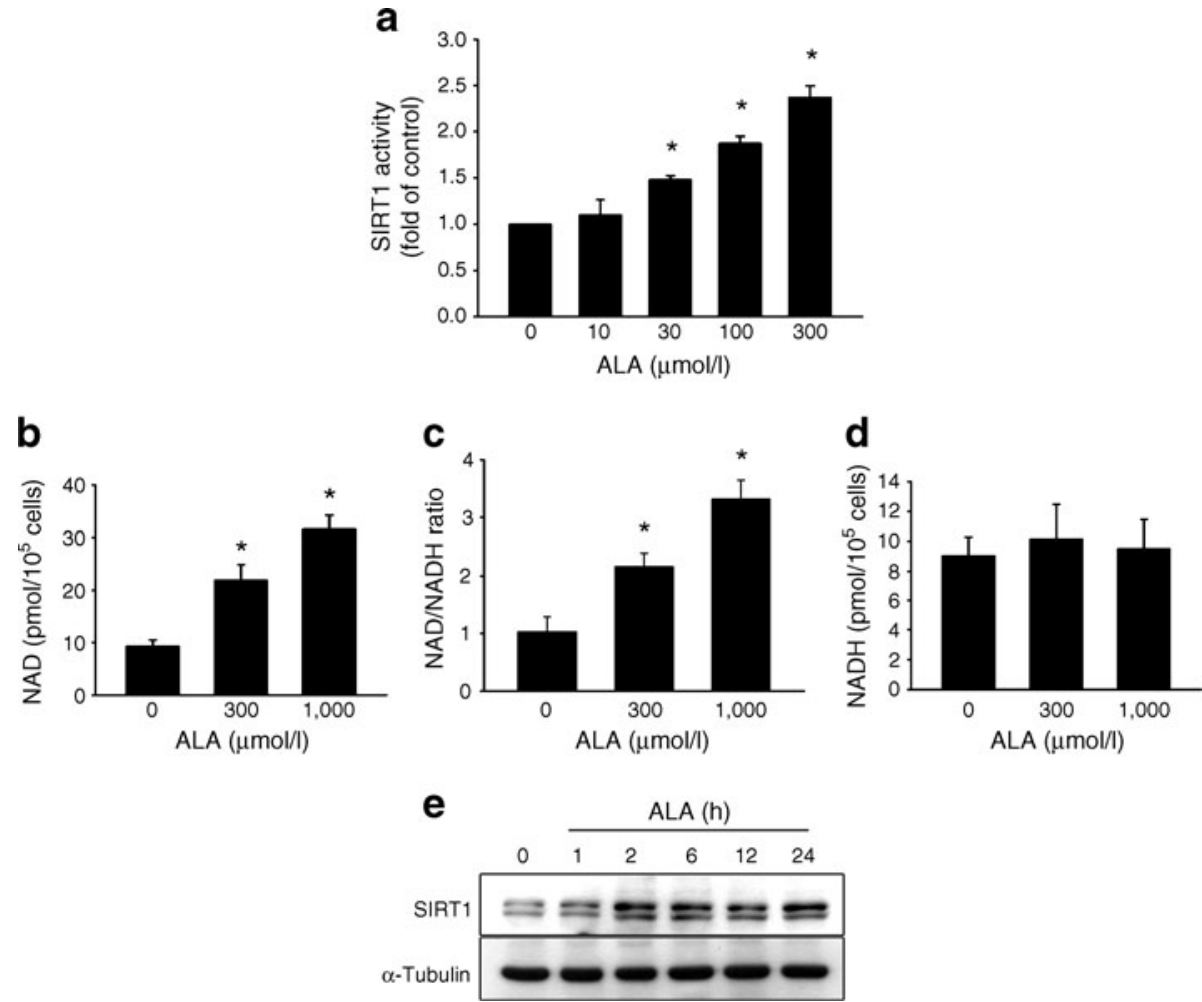
measured the $\mathrm{NAD}^{+} / \mathrm{NADH}$ ratio in $\mathrm{C}_{2} \mathrm{C}_{12}$ myotubes. Treatment of cells with ALA for $24 \mathrm{~h}$ significantly increased $\mathrm{NAD}^{+}$ and the $\mathrm{NAD}^{+} / \mathrm{NADH}$ ratio in $\mathrm{C}_{2} \mathrm{C}_{12}$ myotubes (Fig. $1 \mathrm{~b}$ and d). As an increase in the $\mathrm{NAD}^{+} / \mathrm{NADH}$ ratio is known to induce SIRT1 production, we examined the protein level of SIRT1 in $\mathrm{C}_{2} \mathrm{C}_{12}$ myotubes. As shown in Fig. 1e, treatment with ALA caused an increase in SIRT1 protein levels in $\mathrm{C}_{2} \mathrm{C}_{12}$ myotubes.

a

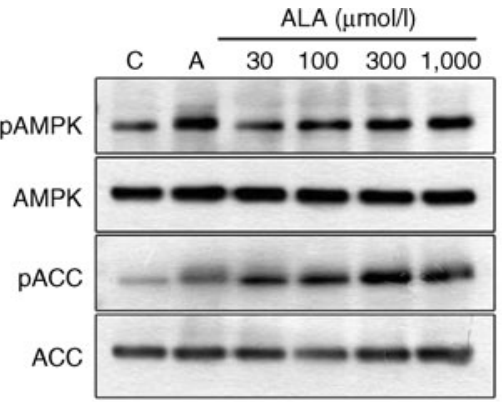

C

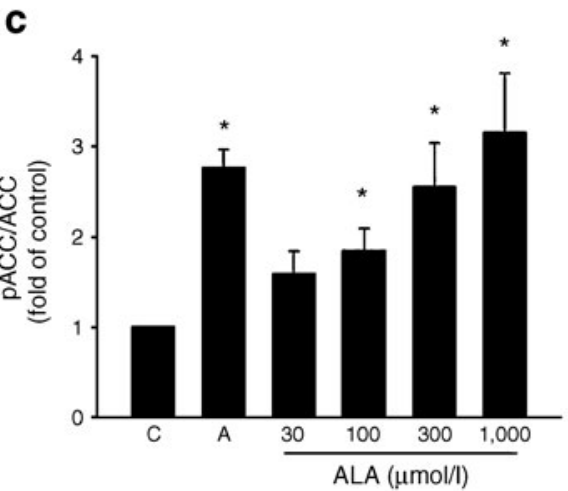

e

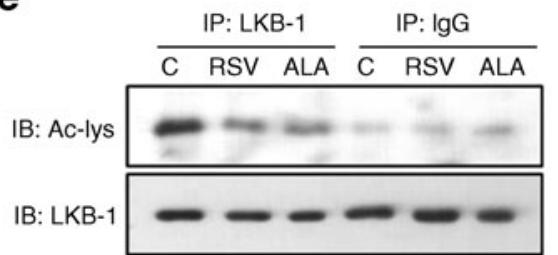

ALA stimulates AMPK phosphorylation and LKB-1 deacetylation AMPK exerts effects similar to SIRT1 on cellular energy metabolism and mitochondrial biogenesis. To investigate whether ALA stimulates the AMPK signalling pathway, we examined the effects of ALA on phosphorylation of AMPK and ACC, a downstream target of AMPK. Figure 2 shows that ALA increased phosphorylation of AMPK and ACC in $\mathrm{C}_{2} \mathrm{C}_{12}$ myotube cells in a concentration-dependent
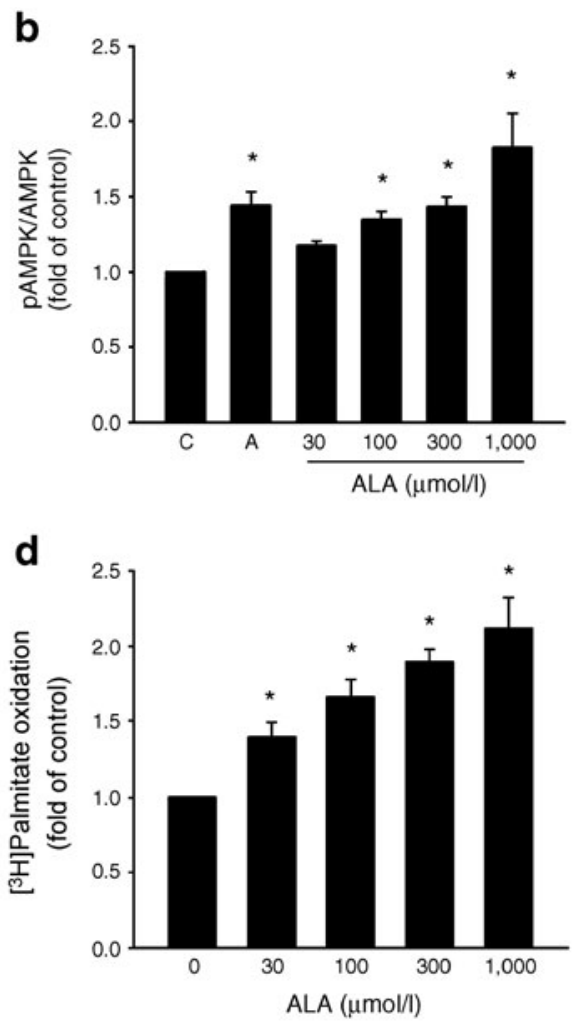

f

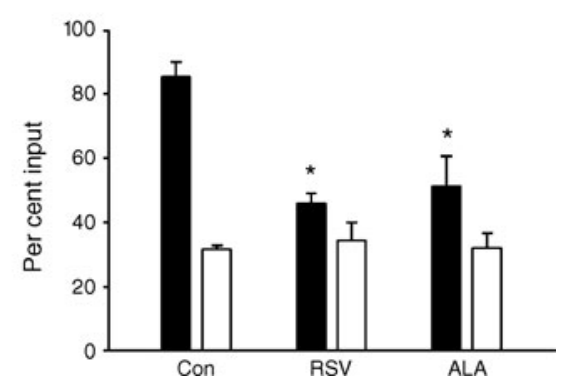

$\beta$-oxidation was assayed as described in the Methods section. Data are expressed as the mean \pm SEM $(n=3)$. ${ }^{*} p<0.05$ compared with the control $(0 \mu \mathrm{mol} / \mathrm{l})$. e $\mathrm{C}_{2} \mathrm{C}_{12}$ myotubes cells treated with ALA $(300 \mu \mathrm{mol} / \mathrm{l})$ for $3 \mathrm{~h}$. Protein lysates were immunoprecipitated (IP) with antibodies to LKB-1, and acetylation level was detected by imunoblotting (IB) with antibodies to acetyl-lysine (Ac-lys). RSV, resveratrol. $\mathbf{f}$ The acetylation levels were normalised to protein input. Data are expressed as the mean \pm SEM $(n=3) .{ }^{*} p<0.05$ compared with the control. Black bar, acetylation; white bar, IgG. Con, control; RSV, resveratrol 
manner (Fig. 2a-c). To determine whether the activation of AMPK promoted fatty acid $\beta$-oxidation, we examined the effect of ALA on palmitate $\beta$-oxidation. ALA (30$1,000 \mu \mathrm{mol} / 1,24 \mathrm{~h}$ ) increased the rate of $\beta$-oxidation in a concentration-dependent manner (Fig. 2d). LKB-1, an upstream regulator of AMPK, has been shown to be regulated by SIRT1-dependent deacetylation [26]. To determine whether SIRT1 regulated LKB-1 deacetylation, the acetylation level of LKB-1 was measured by immunoprecipitation of LKB-1 followed by immunobloting with antibodies to acetyl-lysine. As shown in Fig. 2e, treatment with ALA or resveratrol (a well-known SIRT1 activator) reduced the acetylation level of LKB-1, where the levels of acetylation were normalised to protein input as shown in Fig. 2f. Both resveratrol and ALA significantly reduced LKB-1 acetylation. These data support the notion that SIRT1 may regulate the AMPK signalling pathway through LKB-1 deacetylation [27].

ALA-increased $\left[9,10-{ }^{3} H\right]$ palmitate $\beta$-oxidation is mediated through SIRT1/AMPK signalling To test whether SIRT1 acts as an upstream regulator of AMPK, we investigated the effects of pharmacological inhibitors of SIRT1 (NA) and AMPK (compound $\mathrm{C}$ ) on phosphorylation of AMPK and ACC. As shown in Fig. 3a-c, ALA increased AMPK and ACC phosphorylation, and these effects were blocked by NA, suggesting that SIRT1 acts upstream of AMPK. We next examined the effects of these inhibitors on fatty acid $\beta$-oxidation in $\mathrm{C}_{2} \mathrm{C}_{12}$ cells. ALA increased $\left[9,10-{ }^{3} \mathrm{H}\right]$
Fig. 3 ALA-increased

$\left[9,10-{ }^{3} \mathrm{H}\right]$ palmitate $\beta$-oxidation is mediated through (SIRT1)/

AMPK signalling. a $\mathrm{C}_{2} \mathrm{C}_{12}$ myotubes were pretreated with NA $(1 \mathrm{nmol} / \mathrm{l})$ for $24 \mathrm{~h}$ and compound $\mathrm{C}(20 \mu \mathrm{mol} / \mathrm{l})$ for 30 min before the addition of ALA $(300 \mu \mathrm{mol} / 1)$ for $1 \mathrm{~h}$. b and c Ratios of pAMPK to AMPK and pACC to ACC, respectively, were quantified in three independent experiments per condition. Data are expressed as the mean \pm SEM $(n=3) .{ }^{*} p<0.05$ compared with the control $(0 \mu \mathrm{mol} / \mathrm{l}) . \mathrm{d} \mathrm{C}_{2} \mathrm{C}_{12}$ myotubes were pretreated with compound C $(20 \mu \mathrm{mol} / \mathrm{l})$ or NA $(1 \mathrm{nmol} / \mathrm{l})$ for $24 \mathrm{~h}$ before the addition of ALA $(300 \mu \mathrm{mol} / \mathrm{l})$ for $24 \mathrm{~h}$. $\left[{ }^{3} \mathrm{H}\right]$ Palmitate was added, and fatty acid $\beta$-oxidation was assayed. e $\mathrm{C}_{2} \mathrm{C}_{12}$ cells were transfected with SIRT1 siRNA for $72 \mathrm{~h}$ and then stimulated with ALA for $30 \mathrm{~min}$. Cell lysates were analysed by immunoblotting using antibodies specific for SIRT1, pAMPK, pACC, AMPK and GAPDH. These results represent one of three independent experiments. $\mathrm{f}_{2} \mathrm{C}_{12}$ cells were transfected with SIRT1 siRNA for $72 \mathrm{~h}$. Fatty acid $\beta$-oxidation was examined with $\left[{ }^{3} \mathrm{H}\right]$ palmitate in $\mathrm{C}_{2} \mathrm{C}_{12}$ myotubes. All above data are expressed as the mean \pm SEM $(n=3) . * p<0.05$ compared with the control $(0 \mu \mathrm{mol} / \mathrm{l})$ and $\dagger p<0.05$ compared with ALA treated alone group. AICAR ( $1 \mathrm{mmol} / \mathrm{l})$ was used as a positive control a

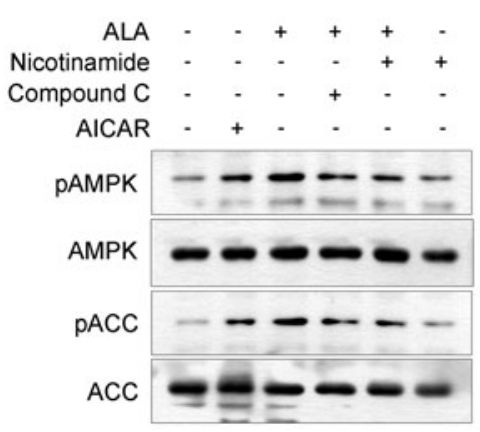

C

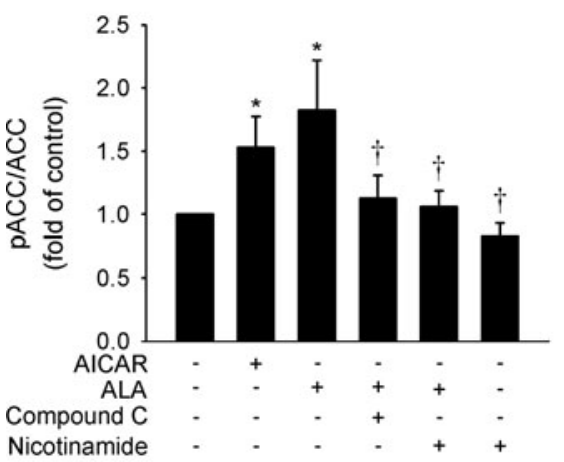

e

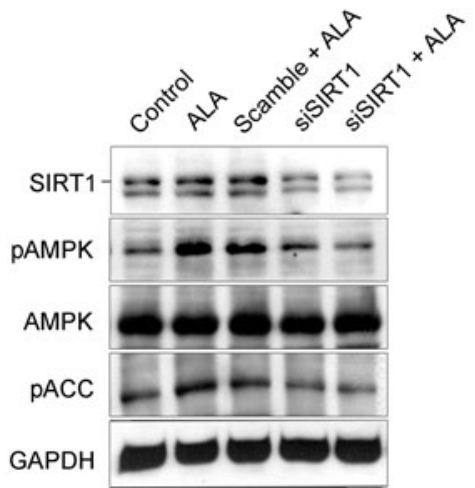

b

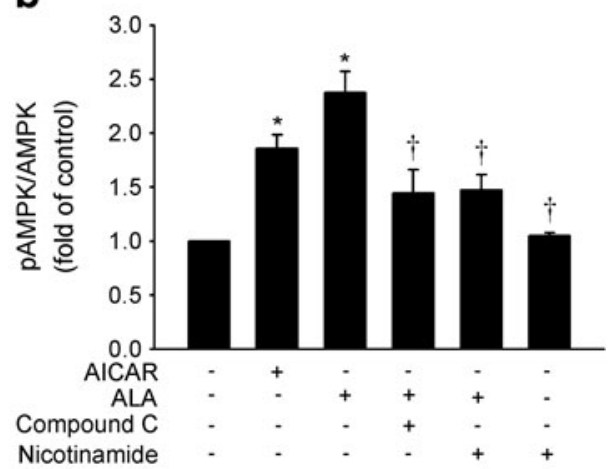

d

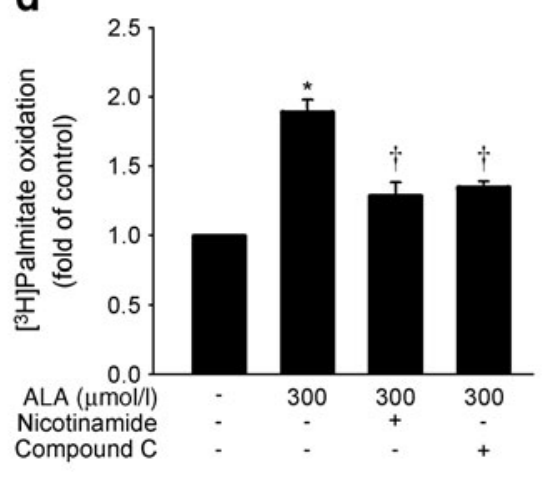

f

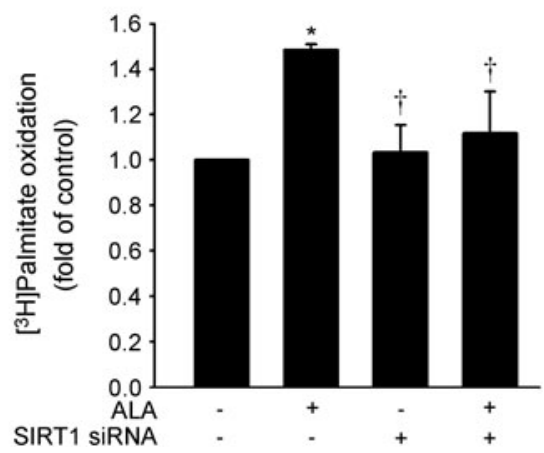


palmitate $\beta$-oxidation in $\mathrm{C}_{2} \mathrm{C}_{12}$ cells, and this effect was inhibited by pretreatment with NA or compound C (Fig. 3d). To further confirm the role of SIRT1 in regulating AMPK activation, SIRT1-specific siRNAs were transfected to knockdown SIRT1 production. Knockdown of SIRT1 significantly decreased ALA-stimulated AMPK and ACC phosphorylation (Fig. 3e) along with a decrease in fatty acid $\beta$-oxidation (Fig. $3 \mathrm{f}$ ). Taken together, our data suggest that ALA stimulates AMPK signalling and increases fatty acid $\beta$-oxidation in a SIRT-1-dependent manner.

ALA regulates lipid metabolism and lowers high-glucoseinduced cellular triacylglycerol accumulation To determine whether ALA is involved in lipid metabolism, we examined the expression of lipid-related proteins in $\mathrm{C}_{2} \mathrm{C}_{12}$ myotubes. The production of FAS was suppressed by treatment of $\mathrm{C}_{2} \mathrm{C}_{12}$ myotubes with ALA $(30-1,000 \mu \mathrm{mol} / \mathrm{l})$ for $24 \mathrm{~h}$. In contrast, treatment with ALA increased the production of ATGL (Fig. 4a). ATGL is a newly discovered lipase, which catalyses the hydrolysis of the first ester bond of stored triacylglycerol [28]. Incubation of cells in high-glucose medium is known to increase lipogenic gene expression and lipid accumulation. Consistently, intracellular triacylglycerol accumulation was increased in the high-glucose condition, and the increase in accumulation was blocked by pretreatment with ALA $(100-1,000 \mu \mathrm{mol} / \mathrm{l})$. To delineate the roles of SIRT1 and AMPK in lipid metabolism, cells were pretreated with a SIRT1 inhibitor (NA) or an AMPK
Fig. 4 ALA regulates metabolism and lowers high-glucose-induced cellular triacylglycerol accumulation. a $\mathrm{C}_{2} \mathrm{C}_{12}$ myotubes were treated with different concentrations of ALA and AICAR (A, $1 \mathrm{mmol} / \mathrm{l})$ for $24 \mathrm{~h}$. Whole-cell lysate protein was examined by western blotting for FAS and ATGL. b $\mathrm{C}_{2} \mathrm{C}_{12}$ myotubes were incubated for $24 \mathrm{~h}$ without or with increasing concentrations of ALA in the absence or presence of $30 \mathrm{nmol} / 1 \mathrm{D}$-glucose (high glucose). Intracellular triacylglycerol contents were measured and are expressed as $\mu \mathrm{g}$ of lipid/mg of protein (mean \pm SEM, $n=3$ ) as described in the Methods section. ${ }^{*} p<0.05$ vs normal glucose; $\uparrow p<0.05$ vs high glucose alone; $₫ p=0.05$. c and $\mathbf{d}$ Cells were pretreated with NA or compound $\mathrm{C}$ for $24 \mathrm{~h}$ and then incubated with ALA for another $24 \mathrm{~h}$. The production of SIRT1, FAS and ATGL was detected by western blotting. Intracellular triacylglycerol was also measured (mean \pm SEM, $n=3 ; * p<0.05$ vs ALA treatment under highglucose treatment). $\mathbf{e}$ and $\mathbf{f}$ Knockdown of SIRT1 by siRNA downregulates SIRT1 production and FAS, ATGL and intracellular triacylglycerol levels in $\mathrm{C}_{2} \mathrm{C}_{12}$ myotubes treated with ALA. ${ }^{*} p<0.05$ vs ALA treatment under high-glucose treatment a

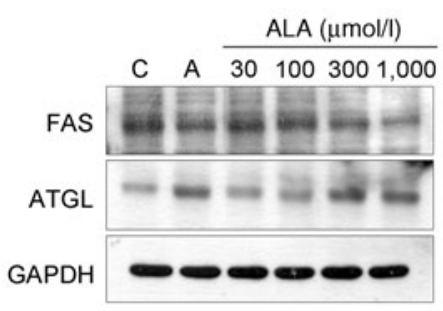

C

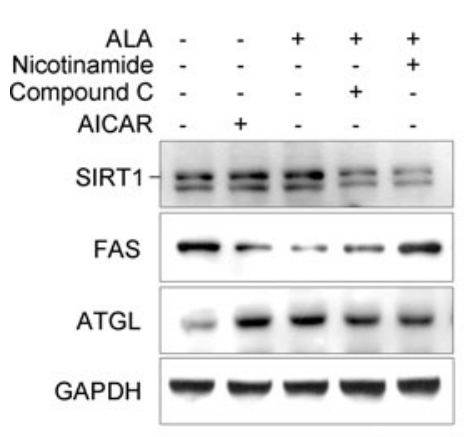

e

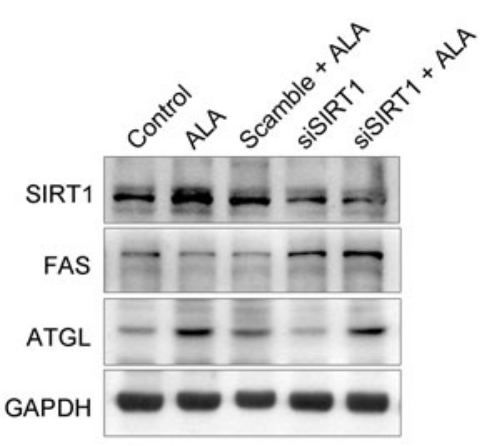

b

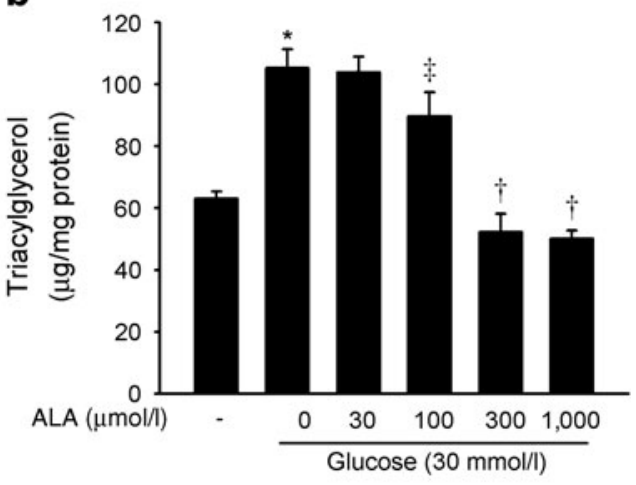

d

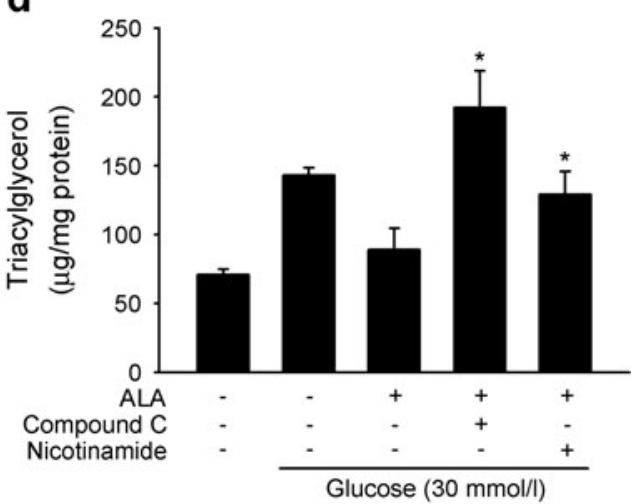

f

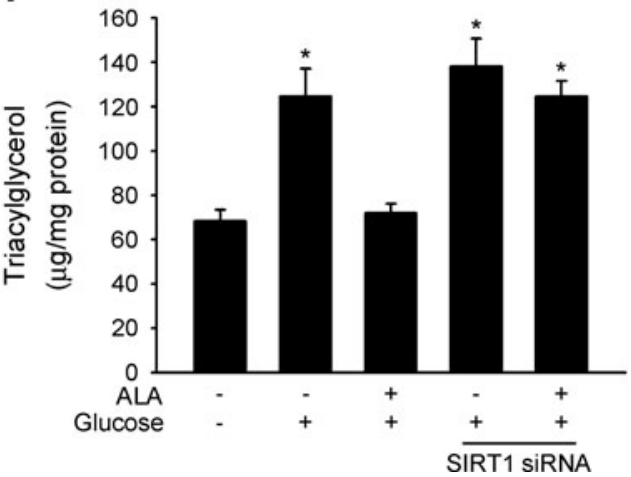


inhibitor (compound C), and their effects on FAS and ATGL production were examined. As shown in Fig. 4c, the effects of ALA on FAS and ATGL production were reversed by the pharmacological inhibitor for AMPK or SIRT1, suggesting that the regulation of these enzymes is mediated through SIRT1 - and AMPK-dependent pathways. Consistently, knockdown of SIRT1 by siRNA reversed the regulation by ALA of FAS and ATGL production (Fig. 4d). Inhibition of SIRT1 and AMPK or knockdown of SIRT1 also attenuated ALA-induced lipid reduction under high-glucose conditions (Fig. 4e, f). These data suggest that ALA protected against high-glucose-induced triacylglycerol accumulation by regulating lipid-related proteins.

ALA ameliorates the metabolic function of mice with STZ/ $N A$-induced diabetes To investigate the effects of ALA on lipid metabolism in vivo, C57BL/6J mice were administered STZ (100 mg/kg) and NA (240 mg/kg), twice with an interval of 2 days. These mice were then fed on a high-fat diet for 4 weeks to induce type 2 diabetes mellitus [22]. ALA was administered daily orally (50 and $200 \mathrm{mg} / \mathrm{kg}$ ) for 1 month. Administration of ALA markedly reduced the mass of visceral fat in mice with STZ/NA-induced diabetes
(Fig. 5a). The fat mass was significantly reduced by ALA treatment. The reductions in the mass of fat cells in 50 and $200 \mathrm{mg} / \mathrm{kg}$-treated mice were 14.36 and $52.58 \%$, respectively (Fig. 5c). The vehicle-treated mice showed normal body weight during the experiment period, whereas ALA treatment at $200 \mathrm{mg} / \mathrm{kg}$ caused a dramatic loss $(\sim 11 \%)$ of body weight (Fig. 5b), and did not improve glucose tolerance in diabetic mice (electronic supplementary material [ESM] Fig. 1). Although the liver weight of ALA-treated mice showed no difference, the liver function index of alanine aminotransferase of ALA-treated mice (18.00 \pm 2.16$)$ was obviously improved compared with that of vehicle-treated mice (54.60土7.23; Table 1). Plasma glucose and triacylglycerol levels were lower in the ALA-treated group at a high dosage (Table 1). These data suggest that the metabolic dysfunction in STZ/NA-induced diabetic mice was alleviated with ALA treatment.

$A L A$ regulates lipid-related proteins, the $N A D^{+} / N A D H$ ratio, and lipid accumulation in STZ/NA-induced diabetic mice To further confirm the changes in FAS and ATGL in vivo, we examined the levels of ATGL, FAS and phosphoAMPK in the liver of STZ/NA-induced diabetic mice. ALA
Fig. 5 ALA ameliorates the metabolic function in mice with STZ- and NA-induced diabetes. a Gross appearance of the whole body and abdomen of diabetic mice treated with vehicle $(50 \%$ alcohol, control, left) or ALA (middle, $50 \mathrm{mg} \mathrm{kg}^{-1}$ day $^{-1}$ [low]; right, $200 \mathrm{mg} \mathrm{kg}^{-1}$ day $^{-1}$ [high]). b Changes in body weight with or without ALA. Diabetic mice were treated with the vehicle (white circle; $n=7$ ) or ALA (upside down black triangle, $50 \mathrm{mg} / \mathrm{kg}, n=7$; white triangle, $200 \mathrm{mg} / \mathrm{kg}, n=6$ ) and the normal group (black circle, $n=5$ ). ${ }^{*} p<0.05$ compared with the vehicle group. $\mathbf{c}$ The mass of visceral fat was measured. ${ }^{*} p<0.05$ compared with the normal group and $\uparrow p<0.05$ compared with diabetic vehicle group. d Western blot analysis of lipid-related protein production in diabetic mice liver with or without ALA. e Intracellular levels of $\mathrm{NAD}^{+}(\mathbf{e}), \mathrm{NADH}$ (f) and the $\mathrm{NAD}^{+} / \mathrm{NADH}$ ratio $(\mathrm{g})$ in the liver of mice treated with high $(200 \mathrm{mg} / \mathrm{kg})$ or low $(50 \mathrm{mg} / \mathrm{kg}$ ) doses of ALA. Results are the mean $\pm \mathrm{SEM}$. $* p<0.05$ a

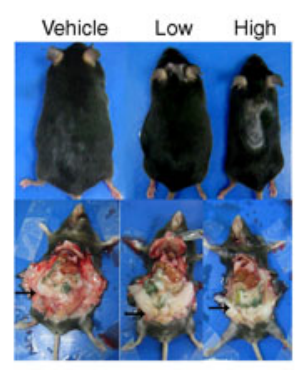

C

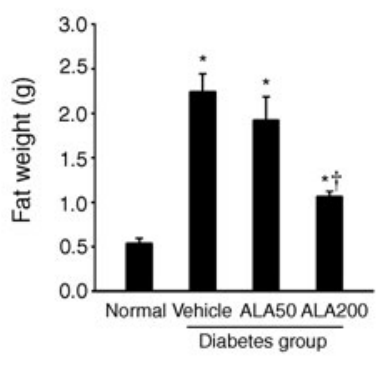

b

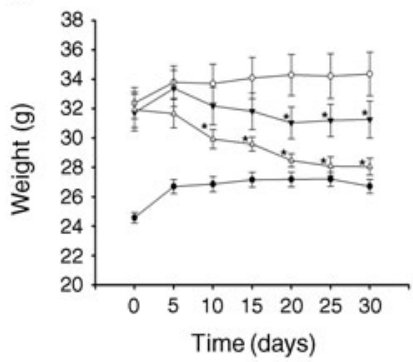

d

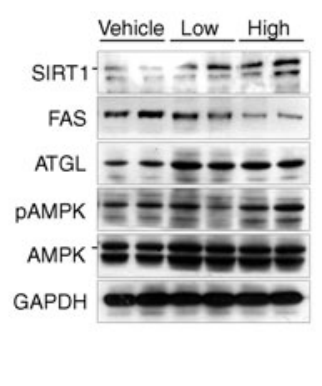

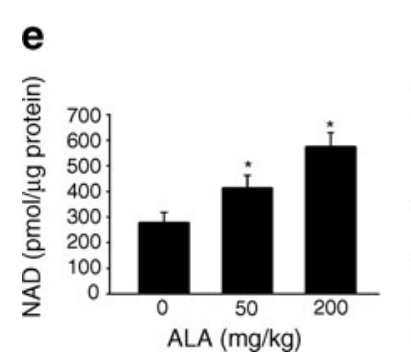

f

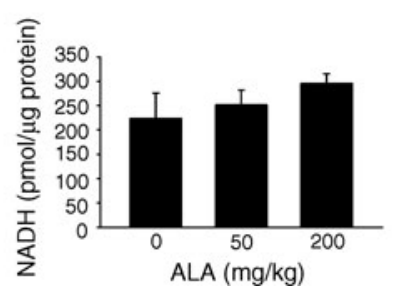

g

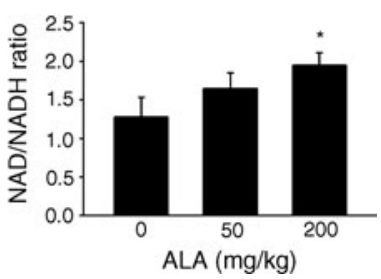


Table 1 Metabolic variables of STZ-treated mice fed on a high-fat $\operatorname{diet}$ (HFD) with or without ALA

Values are mean \pm SEM; $n=7$ ${ }^{*} p<0.05$ compared with control mice; ${ }^{\dagger} p<0.05$ compared with HFD-fed untreated mice

ALT, alanine aminotransferase

\begin{tabular}{lllll}
\hline Variable & Control & HFD & HFD +ALA50 & HFD +ALA200 \\
\hline Body weight $(\mathrm{g})$ & $26.71 \pm 0.47$ & $34.36 \pm 1.47^{*}$ & $31.27 \pm 1.25 \dagger$ & $28.06 \pm 0.58 \dagger$ \\
Epididymis fat weight $(\mathrm{g})$ & $0.53 \pm 0.06$ & $2.23 \pm 0.20^{*}$ & $1.92 \pm 0.27$ & $1.06 \pm 0.06 \dagger$ \\
Liver weight (g) & $0.98 \pm 0.08$ & $1.03 \pm 0.12$ & $1.19 \pm 0.08$ & $1.14 \pm 0.09$ \\
ALT (U/l) & $22.00 \pm 2.55$ & $54.60 \pm 7.23^{*}$ & $19.71 \pm 3.36 \dagger$ & $18.00 \pm 2.16 \dagger$ \\
Plasma glucose (mmol/l) & $7.27 \pm 0.41$ & $11.44 \pm 0.79^{*}$ & $11.10 \pm 0.31$ & $9.50 \pm 0.33 \dagger$ \\
Triacylglycerol (mmol/l) & $0.21 \pm 0.10$ & $0.72 \pm 0.10^{*}$ & $0.63 \pm 0.15$ & $0.41 \pm 0.06 \dagger$ \\
\hline
\end{tabular}

treatment decreased FAS production and increased ATGL and phospho-AMPK levels (Fig. 5d). The NAD ${ }^{+}$level was increased from 278 to $575 \mathrm{pmol} / \mu \mathrm{g}$ protein, and the $\mathrm{NAD}^{+}$/ $\mathrm{NADH}$ ratio was increased by more than $50 \%$ (Fig. $5 \mathrm{e}-\mathrm{g}$ ).
Effects of ALA treatment in db/db mice Because STZ/NAinduced diabetic mice may have unphysiological metabolic conditions, $d b / d b$ mice were used to confirm our observations. ALA was orally administered to 14 -week-old $d b / d b$
Fig. 6 ALA improves lipid accumulation in $d b / d b$ mice. a Gross appearance of the whole body and abdomen of $d b / d b$ mice treated with vehicle $(50 \%$ alcohol, control, left) or ALA (right, $200 \mathrm{mg} \mathrm{kg}^{-1}$ day $^{-1}$ ). b Changes in body weight with or without ALA. The $d b / d b$ mice were treated with the vehicle (white circle; $n=4$ ) or ALA (black circle, $200 \mathrm{mg} / \mathrm{kg}, n=4)$. ${ }^{*} p<0.05$ compared with the vehicle group. The gonadal (c) and visceral (d) fat pads were isolated from control and ALA-treated mice. e Western blot analysis of lipid-related protein production in $d b / d b$ mice liver and muscle with or without ALA. f, g Histopathological sections of muscle and liver from ALA-treated and -untreated $d b / d b$ mice were stained with Oil Red-O and Sudan III to detect the content of lipid droplets. H\&E, haematoxylin and eosin a

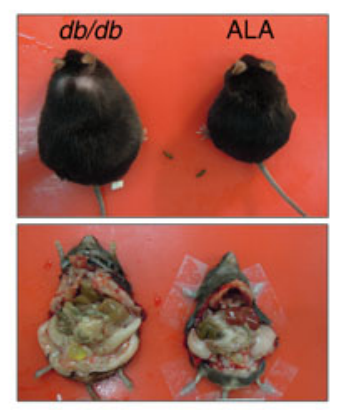

C
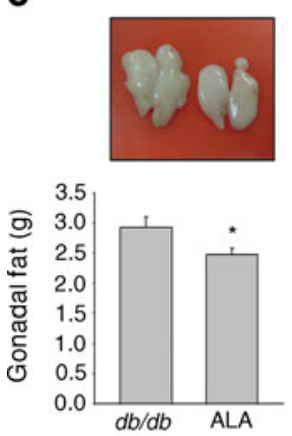

d
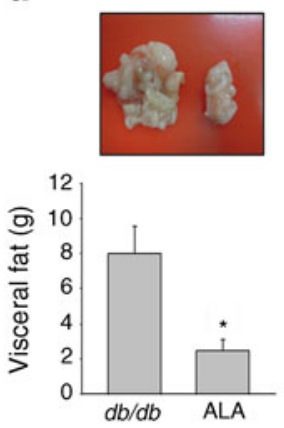

f

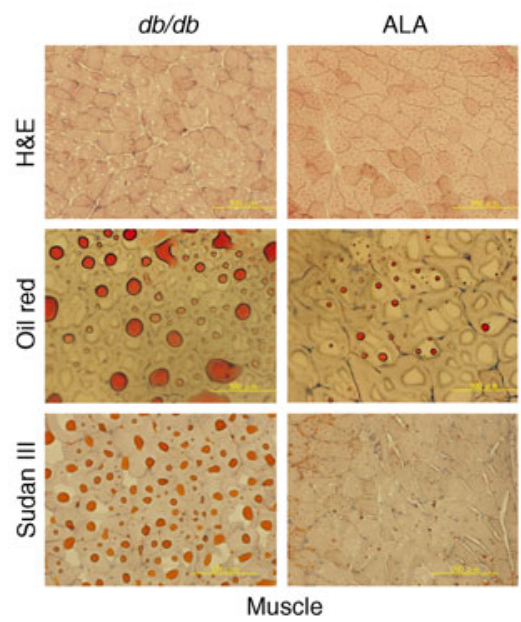

b

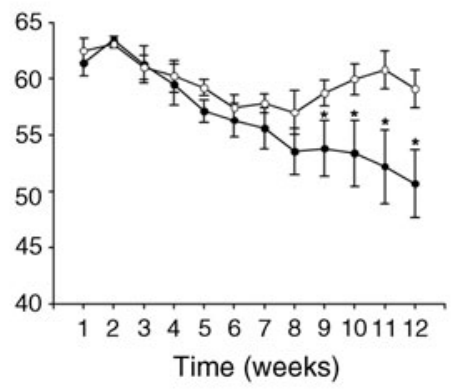

e

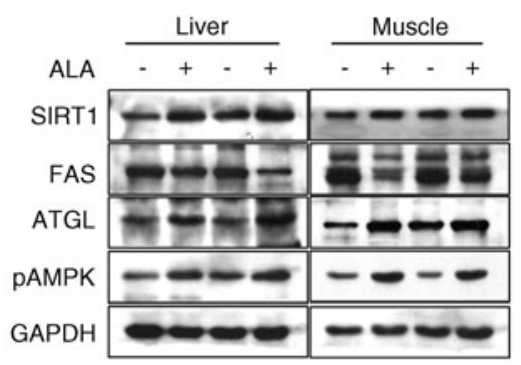

g

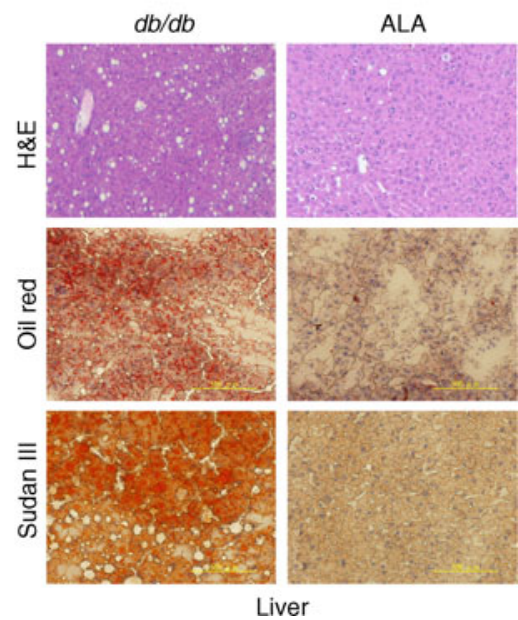


mice for 3 months. ALA administration resulted in a $13 \%$ reduction in body weight compared with the control group (Fig. 6a, b). The gonadal fat tissues were also significantly but slightly decreased in ALA-treated mice (Fig. 6c). The visceral fat content in $d b / d b$ mice was significantly reduced in those treated with ALA (Fig. 6d). Serum triacylglycerol, cholesterol and LDL levels were significantly lower in the ALA-treated group. Blood $\mathrm{HbA}_{1 \mathrm{c}}$ and glucose levels were not significantly altered by ALA treatment (Table 2). ALA treatment did not alter the glucose tolerance in $d b / d b$ mice (ESM Fig. 2). We next assessed the effects of ALA on lipidrelated gene expression in isolated liver and skeletal muscle. Consistent with our in vitro data, the production of ATGL, SIRT1 and phospho-AMPK was upregulated by ALA treatment, whereas FAS was suppressed (Fig. 6e). The liver and muscle sections were stained with Oil Red-O and Sudan III to detect lipid. As shown in Fig. 6f,g, fewer lipid droplets were observed in ALA-treated mice than in the untreated group.

\section{Discussion}

Obesity, dyslipidaemia and metabolic syndrome are increasingly prevalent due to excess energy intake and nutrient availability. Energy restriction and exercise may prevent metabolic disorders, but are seldom successful. Thus there is an unmet medical need to develop therapeutic agents that mimic energy restriction and exercise to combat metabolic disorders. SIRT1 is thought to play a pivotal role in metabolic adaptation to energy restriction, and is proposed as a potential target for treating metabolic disorders. This study provides the first evidence that SIRT1 is a target of ALA.

Table 2 Effect of ALA on metabolic variables of $d b / d b$ mice

\begin{tabular}{lll}
\hline Variable & Control $(n=4)$ & ALA $(n=4)$ \\
\hline Serum & & \\
AST (U/l) & $219.00 \pm 30.87$ & $162.00 \pm 46.41$ \\
ALT (U/l) & $138.00 \pm 17.32$ & $127.00 \pm 15.67$ \\
Cholesterol (mmol/l) & $3.26 \pm 0.30$ & $2.29 \pm 0.10^{*}$ \\
Triacylglycerol (mmol/l) & $3.15 \pm 0.16$ & $1.35 \pm 0.12^{*}$ \\
HDL-cholesterol (mmol/l) & $84.75 \pm 8.17$ & $82.00 \pm 10.95$ \\
LDL-cholesterol (mmol/l) & $18.75 \pm 1.71$ & $8.75 \pm 2.78^{*}$ \\
Whole blood $_{\text {Glucose (mmol/l) }}$ & \\
HbA $_{1 \mathrm{c}}(\%)$ & $20.54 \pm 2.80$ & $18.93 \pm 1.30$ \\
HbA $_{1 \mathrm{c}}(\mathrm{mmol} / \mathrm{mol})$ & $8.60 \pm 1.03$ & $6.43 \pm 0.86$ \\
\hline
\end{tabular}

Values are mean $\pm \operatorname{SEM}(n=4) ; \operatorname{ALA} 200 \mathrm{mg} / \mathrm{kg}$

${ }^{*} p<0.05$ compared with control group

ALT, alanine aminotransferase; AST, aspartate aminotransferase
ALA activated SIRT1 in a cell-free system, and ALA also increased the $\mathrm{NAD}^{+} / \mathrm{NADH}$ ratio and upregulated SIRT1 in $\mathrm{C}_{2} \mathrm{C}_{12}$ myotubes. Furthermore, we demonstrated that ALA enhanced fatty acid $\beta$-oxidation, increased ATGL production, and decreased FAS production through the SIRT1/ AMPK signalling pathway.

ALA is a strong antioxidant which can be reduced to dihydrolipoase by either mitochondrial lipoamide dehydrogenase or the thioredoxin/thioredoxin reductase system to increase the $\mathrm{NAD}^{+} / \mathrm{NADH}$ ratio. The ability of ALA to increase $\mathrm{NAD}^{+}$and the $\mathrm{NAD}^{+} / \mathrm{NADH}$ ratio may explain, at least in part, how ALA treatment increases SIRT1 activity. On the other hand, activation of AMPK was linked to SIRT1 protein production in skeletal muscle cells [29]. As ALA activates AMPK, another possibility is that ALA induces SIRT1 production through AMPK activation. ALA-stimulated AMPK phosphorylation was inhibited by the SIRT1 inhibitor, suggesting that SIRT1 acts as an upstream activator of AMPK. These observations were further confirmed by the knockdown of SIRT1, which also reduced AMPK phosphorylation in $\mathrm{C}_{2} \mathrm{C}_{12}$ myotubes. Our results agree with those of $\mathrm{Hou}$ et al [30], who showed that polyphenols mediate lipid-lowering effects through the SIRT1/ LKB1/AMPK signalling pathway in HepG2 cells. Our results are in line with those of Lan et al [31], who demonstrated that SIRT1 leads to deacetylation of a lysine residue on LKB-1 to activate AMPK. However, these results differ from the findings of Canto et al [32], who showed that AMPK acted upstream of SIRT1 by modulating NAD ${ }^{+}$ metabolism. AMPK has been shown to increase SIRT1 activity by regulating NAMPT, an $\mathrm{NAD}^{+}$-biosynthetic enzyme [33]. On the other hand, SIRT1 was upregulated by the p53/FOXO3a complex [14], and AMPK has been shown to regulate FOXO1 activity through phosphorylation [34]. Although AMPK and SIRT1 can activate each other in different orders, the two molecules have similar effects on energy metabolism. These findings support the notion that cellular metabolism is regulated in a concerted manner.

We demonstrated that oral administration of ALA decreased body weight and visceral fat mass in diabetic mice fed on a high-fat diet and in $d b / d b$ mice. The lipid-lowering effect of ALA was associated with increased ATGL and suppressed FAS protein production in liver and skeletal muscle of both STZ/NA-induced and $d b / d b$ diabetic mice. These responses were attenuated by inhibition of SIRT1 or AMPK, suggesting that these lipid metabolism-related proteins were regulated through a SIRT1/AMPK-dependent pathway. These results agree with those reported by Hou et al, who showed that activation of SIRT1 by resveratrol exerted a lipid-lowering effect though AMPK [30]. These data also agree with those of Gaidhu et al [35], who reported that AICAR induces AMPK activation, which promotes energy dissipation through ATGL induction. On the other 
hand, it is well known that AMPK phosphorylates and inhibits ACC activity, which in turn increases fatty acid oxidation. Inhibition of FAS, a lipogenic enzyme, is another important consequence of AMPK activation by ALA. These findings are in accordance with results of previous studies showing that FAS gene expression was abrogated by treatment with AICAR in hepatocytes [36]. These results define a novel mechanism by which ALA has a lipid-lowering effect by activating SIRT1 and AMPK and by regulating lipid-related proteins of ACC, ATGL and FAS. These observations are consistent with results showing amelioration of insulin sensitivity and triacylglycerol clearance by ALA in skeletal muscle and liver [8]. However, the impaired glucose tolerance was not improved by ALA treatment in either STZ/NA-induced or $d b / d b$ diabetic mice (ESM Figs 1 and 2). Although $\mathrm{HbA}_{1 \mathrm{c}}$ was slightly reduced, the differences between treated and untreated groups were not statistically significant (Table 2). These data suggest that treatment with ALA alone may have limitations for exerting an antiglycaemic effect.

Taken together, ALA exerts an anti-obesity effect by activating the SIRT1/AMPK signalling pathway. This study demonstrates novel pharmacological actions of ALA, including activation of SIRT1 in muscle cells and regulation of lipid-related proteins. ALA not only enhances fatty acid oxidation but also promotes a lipid-lowering effect by regulating $F A S$ and $A T G L$ expression. Oral administration of ALA decreased body weight and the visceral fat content of both $d b / d b$ and STZ/NA-induced diabetic mice.

Funding This study was supported by grants NSC 99-3112-B-166001 and NSC 98-3112-B-038-001 from the National Science Council, Taipei, Taiwan.

Duality of interest The authors declare that there is no duality of interest associated with this manuscript.

Contribution statement H-ML, S-GW and W-LC contributed to conception and design of the study; W-LC and C-HK contributed to analysis and interpretation of data. W-LC and H-ML drafted the article and S-GW, W-LC and C-HK revised the article for intellectual content. All authors gave final approval of the version to be published.

\section{References}

1. Reed LJ (2001) A trail of research from lipoic acid to alpha-keto acid dehydrogenase complexes. J Biol Chem 276:38329-38336

2. Kim MS, Park JY, Namkoong C et al (2004) Anti-obesity effects of alpha-lipoic acid mediated by suppression of hypothalamic AMPactivated protein kinase. Nat Med 10:727-733

3. Evans JL, Goldfine ID (2000) Alpha-lipoic acid: a multifunctional antioxidant that improves insulin sensitivity in patients with type 2 diabetes. Diabetes Technol Ther 2:401-413
4. Lee DH, Park DB, Lee YK et al (2005) The effects of thiazolidinedione treatment on the regulations of aquaglyceroporins and glycerol kinase in OLETF rats. Metabolism 54:12821289

5. Yaworsky K, Somwar R, Ramlal T, Tritschler HJ, Klip A (2000) Engagement of the insulin-sensitive pathway in the stimulation of glucose transport by alpha-lipoic acid in 3T3-L1 adipocytes. Diabetologia 43:294-303

6. Konrad T, Vicini P, Kusterer K et al (1999) Alpha-lipoic acid treatment decreases serum lactate and pyruvate concentrations and improves glucose effectiveness in lean and obese patients with type 2 diabetes. Diabetes Care 22:280-287

7. Eason RC, Archer HE, Akhtar S, Bailey CJ (2002) Lipoic acid increases glucose uptake by skeletal muscles of obese-diabetic ob/ ob mice. Diabetes Obes Metab 4:29-35

8. Butler JA, Hagen TM, Moreau R (2009) Lipoic acid improves hypertriglyceridemia by stimulating triacylglycerol clearance and downregulating liver triacylglycerol secretion. Arch Biochem Biophys 485:63-71

9. Guarente L (2006) Sirtuins as potential targets for metabolic syndrome. Nature 444:868-874

10. Brunet A, Sweeney LB, Sturgill JF et al (2004) Stress-dependent regulation of FOXO transcription factors by the SIRT1 deacetylase. Science 303:2011-2015

11. Langley E, Pearson M, Faretta M et al (2002) Human SIR2 deacetylates p53 and antagonizes PML/p53-induced cellular senescence. EMBO J 21:2383-2396

12. Gerhart-Hines Z, Rodgers JT, Bare O et al (2007) Metabolic control of muscle mitochondrial function and fatty acid oxidation through SIRT1/PGC-1alpha. EMBO J 26:1913-1923

13. Funk JA, Odejinmi S, Schnellmann RG et al (2010) SRT1720 induces mitochondrial biogenesis and rescues mitochondrial function after oxidant injury in renal proximal tubule cells. J Pharmacol Exp Ther 333:593-601

14. Rutanen J, Yaluri N, Modi S et al (2010) SIRT1 mRNA expression may be associated with energy expenditure and insulin sensitivity. Diabetes 59:829-835

15. de Kreutzenberg SV, Ceolotto G, Papparella I et al (2010) Downregulation of the longevity-associated protein sirtuin 1 in insulin resistance and metabolic syndrome: potential biochemical mechanisms. Diabetes 59:1006-1015

16. Vinciguerra M, Fulco M, Ladurner A, Sartorelli V, Rosenthal N (2010) SirT1 in muscle physiology and disease: lessons from mouse models. Dis Model Mech 3:298-303

17. Winder WW, Holmes BF (2000) Insulin stimulation of glucose uptake fails to decrease palmitate oxidation in muscle if AMPK is activated. J Appl Physiol 89:2430-2437

18. Jager S, Handschin C, St-Pierre J, Spiegelman BM (2007) AMPactivated protein kinase (AMPK) action in skeletal muscle via direct phosphorylation of PGC-1alpha. Proc Natl Acad Sci U S A 104:12017-12022

19. Ouadda AB, Levy E, Ziv E et al (2009) Increased hepatic lipogenesis in insulin resistance and Type 2 diabetes is associated with AMPK signalling pathway up-regulation in Psammomys obesus. Biosci Rep 29:283-292

20. Lagouge M, Argmann C, Gerhart-Hines Z et al (2006) Resveratrol improves mitochondrial function and protects against metabolic disease by activating SIRT1 and PGC-1 alpha. Cell 127:11091122

21. Wang YX, Lee CH, Tiep S et al (2003) Peroxisome-proliferatoractivated receptor delta activates fat metabolism to prevent obesity. Cell 113:159-170

22. Nakamura T, Terajima T, Ogata T et al (2006) Establishment and pathophysiological characterization of type 2 diabetic mouse model produced by streptozotocin and nicotinamide. Biol Pharm Bull 29:1167-1174 
23. Kume S, Uzu T, Kashiwagi A, Koya D (2010) SIRT1, a calorie restriction mimetic, in a new therapeutic approach for type 2 diabetes mellitus and diabetic vascular complications. Endocr Metab Immune Disord Drug Targets 10:16-24

24. Lomb DJ, Laurent G, Haigis MC (2009) Sirtuins regulate key aspects of lipid metabolism. Biochim Biophys Acta 1804:16521657

25. Howitz KT, Bitterman KJ, Cohen HY et al (2003) Small molecule activators of sirtuins extend Saccharomyces cerevisiae lifespan. Nature 425:191-196

26. Alessi DR, Sakamoto K, Bayascas JR (2006) LKB1-dependent signaling pathways. Annu Rev Biochem 75:137-163

27. Zheng Z, Chen H, Li J et al (2012) Sirtuin 1-mediated cellular metabolic memory of high glucose via the LKB1/AMPK/ROS pathway and therapeutic effects of metformin. Diabetes 61:217228

28. Zimmermann R, Strauss JG, Haemmerle G et al (2004) Fat mobilization in adipose tissue is promoted by adipose triglyceride lipase. Science 306:1383-1386

29. Suwa M, Nakano H, Radak Z, Kumagai S (2010) Short-term adenosine monophosphate-activated protein kinase activator 5-aminoimidazole-4-carboxamide-1-beta-d-ribofuranoside treatment increases the sirtuin 1 protein expression in skeletal muscle. Metabolism 60:393-403
30. Hou X, Xu S, Maitland-Toolan KA et al (2008) SIRT1 regulates hepatocyte lipid metabolism through activating AMP-activated protein kinase. J Biol Chem 283:20015-20026

31. Lan F, Cacicedo JM, Ruderman N, Ido Y (2008) SIRT1 modulation of the acetylation status, cytosolic localization, and activity of LKB1. Possible role in AMP-activated protein kinase activation. J Biol Chem 283:27628-27635

32. Canto C, Gerhart-Hines Z, Feige JN et al (2009) AMPK regulates energy expenditure by modulating NAD+ metabolism and SIRT1 activity. Nature 458:1056-1060

33. Fulco M, Cen Y, Zhao P et al (2008) Glucose restriction inhibits skeletal myoblast differentiation by activating SIRT1 through AMPK-mediated regulation of Nampt. Dev Cell 14:661-673

34. Nemoto S, Fergusson MM, Finkel T (2004) Nutrient availability regulates SIRT1 through a forkhead-dependent pathway. Science 306:2105-2108

35. Gaidhu MP, Fediuc S, Anthony NM et al (2009) Prolonged AICAR-induced AMP-kinase activation promotes energy dissipation in white adipocytes: novel mechanisms integrating HSL and ATGL. J Lipid Res 50:704-715

36. Woods A, Azzout-Marniche D, Foretz M et al (2000) Characterization of the role of AMP-activated protein kinase in the regulation of glucose-activated gene expression using constitutively active and dominant negative forms of the kinase. Mol Cell Biol 20:6704-6711 